\title{
Effects of hot water pre-extraction on surface properties of bagasse soda pulp
}

\author{
Nereida Cordeiro ${ }^{\text {a }}$, Alireza Ashori ${ }^{b}, *$, Yahya Hamzeh ${ }^{c}$, Marisa Faria ${ }^{a}$ \\ a Competence Center in Exact Science and Engineering, University of Madeira, Funchal, Portugal \\ b Department of Chemical Technologies, Iranian Research Organization for Science and Technology (IROST), P.O. Box 15815-3538, Tehran, Iran \\ c Department of Wood and Paper Science and Technology, Faculty of Natural Resources, University of Tehran, Karaj, Iran
}

\section{A R T I C L E I N F O}

\section{Article history:}

Received 30 June 2012

Received in revised form 30 August 2012

Accepted 17 October 2012

Available online 23 October 2012

\section{Keywords:}

Hot water pre-extraction

Inverse gas chromatography (IGC)

Bagasse

Pulping

Surface properties

\begin{abstract}
A B S T R A C T
In this work, the effects of hot water pre-extraction of depithed bagasse on the soda pulping and surface properties were studied. The conditions of hot water pre-extraction were: maximum temperature $170{ }^{\circ} \mathrm{C}$, heat-up time $90 \mathrm{~min}$, time at maximum temperature $10 \mathrm{~min}$, and solid to liquor ratio (S:L) 1:8. Consequently, the pre-extracted and un-extracted bagasse chips were subjected to soda pulping at $160^{\circ} \mathrm{C}$ for $1 \mathrm{~h}$ with 11,14 and $17 \%$ active alkali charge and an S:L of 1:5. The results showed that the hot water pre-extraction increased bagasse surface texture porosity by hemicellulose degradation. Therefore, the delignification was faster for pulping of pre-extracted samples. At a certain charge of alkali, pre-extracted samples showed higher screened yield and lower Kappa number. For instance, at 17\% alkali charge, pre-extracted bagasse gave $11.3 \%$ higher pulp yield compared with the un-extracted ones. Inverse gas chromatography (IGC) results showed that the hot water pre-extraction changed the active sites on the bagasse surface, decreasing the dispersive energy and the basicity character, and affected the particle morphology. The pulping process decreased the hydrophobicity and the basicity of the bagasse surface. The surfaces of un-extracted and pre-extracted bagasse pulps had similar properties but different morphology. The pulps present higher surface area and permeability with more reactive capacity.
\end{abstract}

(c) 2012 Elsevier B.V. All rights reserved.

\section{Introduction}

In recent years, interest in the isolation of hemicelluloses from woody biomass has greatly increased [1-5]. Several researchers have studied the different types of hemicellulose extractions, such as hot water extraction (autohydrolysis), and alkaline and acidic extraction on several wood and non-wood species [5-10]. Some of these studies have focused on the impact of extractions on the pulp properties prepared from pre-extracted wood $[3,4,10,11]$. In general, they reported that it was possible to partially remove hemicelluloses from the chips, without detrimentally affecting the pulp's yield or its quality [5,10].

Although several studies have tried to determine the effect of the hemicellulose removal, namely via hot water pre-extraction, these studies have focused mainly on the final product properties, i.e., the paper properties [4-8]. So far a very little research has been done on the effect of hot water pre-extraction on the pulp characteristics and surface properties. Sousa et al. [12] investigated the effect of surface composition (and therefore hemicellulose content) on the fibers' total surface charge and zeta potential (using a Mütek SZP 06). They observed that a change in hemicellulose content (achieved by modified pulping) from 20 to $15 \%$ decreased the total charge of the fibers (cationic demand) but did not affect the zeta potential, whereas the

\footnotetext{
* Corresponding author. Tel.: +98 215627 6637; fax: +98 2156276265 .

E-mail address: ashori@irost.org (A. Ashori).
}

removal of lignin from the fibers (via bleaching) contributed to a decrease (in magnitude) of the zeta potential. Duarte [3] reported that there is an increase in the surface roughness as extraction takes place, which is also reflected in the increase of the kink index. From a chemical characterization point of view, the removal of hemicelluloses increases the eucalyptus' surface energy and decreases the pulps' acid-base character. For sugar maple, the dispersive component of the surface energy decreases and the acid character is actually increased.

The hydrophilicity is an intrinsic property of woody biomass and together with the porosity permits woody materials to absorb liquid water. The affinity between wood and water has profound impact on physical and mechanical properties. To know this affinity is important in all the pulping processes. Extractives often form coatings on the wood cell walls, playing an important role in the wood hydrophilicity and hydrophobicity. Resin, fatty acids, steroids and steryl esters are the more hydrophobic extractives while the phenolic and polar organic extractives have a hydrophilic character. The hydrophilicity also comes from the accessible hydroxyls on the surface [13]. A hydroxyl could belong to the cellulose, hemicellulose or lignin chains. Therefore, the changes in the hydrophilicity are associated with the components removal and/or structural organization. As these alterations are reflected in the surface properties, the inverse gas chromatography (IGC) was used to determine the effect of the hot water pre-extraction and the pulping process on bagasse material [14]. The hydrophilicity and particle morphology changes were monitored 
by the dispersive component of surface energy $\left(\gamma_{\mathrm{S}}^{\mathrm{D}}\right)$, the monolayer capacity $\left(\mathrm{n}_{\mathrm{m}}\right)$, the surface area $\left(\mathrm{S}_{\mathrm{BET}}\right)$, the permeability $(\mathrm{DP})$ and the surface heterogeneity parameters, obtained by the injection of the $n$-alkane probes (heptane, octane, nonane and decane). To study the surface acid-base character, a series of polar probes (tetrahydrofuran, ethyl acetate, acetone, acetonitrile and ethanol) were used to determine the specific free energy of adsorption parameter $\left(\Delta \mathrm{G}_{\mathrm{ads}}^{\mathrm{sp}}\right.$ ), which were converted into acid-base constants [15].

In this paper, hot water pre-extraction of bagasse, a low cost byproduct of the sugarcane extraction, was carried out in order to recover hemicelluloses based on biorefinery concept. This study was divided in two different parts. In the first part, the effects of pre-extraction on the soda pulping were investigated and compared with the un-extracted samples. In the second part, the impacts of pre-extraction on the surface properties in terms of dispersive surface free energy and acid-base surface character were evaluated using IGC.

\section{Materials and methods}

\subsection{Raw material}

The lignocellulosic material was supplied by the Khouzestan Cultivation and Industry Co., Iran. First, the bagasse stalks were depithed and cut to $2-3 \mathrm{~cm}$ in length. They were then washed, air-dried and screened through a series of screens to remove dirt. For the chemical analysis, the depithed bagasse was ground using a Wiley mill and the fraction passing $2 \mathrm{~mm}$ holes was stored in plastic bags for experiments.

\subsection{Hot water pre-extraction}

Bagasse chips were contacted with water in an electrically heated oil bath containing 4 bombs of $2.5 \mathrm{~L}$ capacity. The bombs were rotated at $1 \mathrm{rpm}$. The conditions of hot water pre-extraction were: maximum temperature $170{ }^{\circ} \mathrm{C}$, heat-up time $90 \mathrm{~min}$, dwell time at maximum temperature $10 \mathrm{~min}$ and solid to liquor ratio $(\mathrm{S}: \mathrm{L}) \mathrm{1:8}$. At the end of the treatment, the solid residue was recovered by filtration and washed with distilled water to remove dissolved substances. The solid fraction (named pre-extracted) was used for the following soda pulping process.

\subsection{Pulping process}

Pulps from raw bagasse and pre-extracted bagasse were obtained in the same reactor used in the hot water pre-extraction process. The cooking conditions were as follows: initial S:L ratio 1:5, temperature $160{ }^{\circ} \mathrm{C}$ and pulping time $60 \mathrm{~min}$. All the above-mentioned conditions were kept constant for pre-extracted and un-extracted materials. The amounts of active alkali were 11,14 and $17 \%$. After cooking, the pulps were thoroughly washed with fresh water on a fine filter, and then disintegrated in a hydropulper at 30,000 revolutions and $0.5 \%$ consistency for $5 \mathrm{~min}$. Disintegrated pulps were screened with vibratory flat screen (with a bedplate of $0.15 \mathrm{~mm}$ slit openings) to determine the screened rejects (pulp shives) and screened yield. Kappa numbers for all samples were determined according to TAPPI Standard T 236 om-99.

\subsection{IGC}

IGC derives from the conventional gas chromatography (GC) technique. In GC, a known stationary phase is used to separate and identify solutes in a mixture, according to their interaction with that stationary phase. In IGC the technique is inverted, but the principle is the same. A known probe is injected into a column packed with the (unknown) stationary sample. The injected probes are adsorbed on the surface of the sample and the retention time is measured in each case. This retention time is dependent on the affinity (interaction) between the sample and probe, and therefore, it allows quantifying these interactions and learning about the surface energetics. Therefore, IGC was employed to evaluate the effect of hot water pre-extraction in the fibers' surface energetics. Fig. 1 shows a schematic comparison of the principle behind GC and IGC techniques.

IGC measurements were carried out on a commercial inverse gas chromatograph (Surface Measurement Systems, London, UK), as exhaustively described by Cordeiro et al. [14]. In this particular work, about $0.5 \mathrm{~g}$ of each sample (un-extracted and pre-extracted) was packed in standard glass silanized (dymethyldichlorosilane; Repelcote $\mathrm{BDH}, \mathrm{UK}$ ) columns, with $300 \mathrm{~mm}$ length and an internal diameter of $3 \mathrm{~mm}$. Four $n$-alkanes (heptane, octane, nonane and decane) were used to measure the dispersive component of the surface energy $\left(\gamma_{\mathrm{S}}^{\mathrm{D}}\right)$. Five polar probes: tetrahydrofuran, ethyl acetate, ethanol, acetone and acetonitrile were used to study the Gibbs specific free energy and acid-base surface character $\left(K_{a}\right.$ and $\left.K_{b}\right)$. The DP studies were done with $n$-octane, tetrahydrofuran and ethanol at different flow rates. The isotherm experiment, used to determine the monolayer capacity $\left(\mathrm{n}_{\mathrm{m}}\right)$ and the surface area $\left(\mathrm{S}_{\mathrm{BET}}\right)$, was undertaken with n-octane. All the experiments were performed at $298 \mathrm{~K}$ and $0 \% \mathrm{RH}$. The experiments were done in duplicate and the presented results are the average values. The experimental error due to the temperature variation, flow rate and retention time measurements was estimated to be less than $4 \%$.

\section{Results and discussion}

\subsection{Raw material characteristics}

The raw bagasse material shows a $\gamma_{\mathrm{S}}^{\mathrm{D}}$ of $46.00 \mathrm{~mJ} / \mathrm{m}^{2}$ (Table 1 ), similar to the values reported by Cordeiro et al., [17-20] and Mills et al. [21] for different non-wood materials (from 37.17 to $51.37 \mathrm{~mJ} / \mathrm{m}^{2}$ ). The results obtained for acid-base characterization show a $K_{a}$ of 0.09 and $a K_{b}$ of 0.26 , indicative of the predominant basic active sites $\left(\mathrm{K}_{\mathrm{b}} / \mathrm{K}_{\mathrm{a}}=2.89\right)$ in the bagasse surface. These results are comparable to the ones obtained for the non-wood materials [17-20].

To obtain information about the $\mathrm{S}_{\mathrm{BET}}$ and $\mathrm{n}_{\mathrm{m}}$, the isotherm experiment was done with the $n$-octane probe, using the BET approach [22]. The obtained results are presented in Table 2. The bagasse under study presents a $S_{B E T}$ of $0.80 \mathrm{~m}^{2} / g$ and a $n_{m}$ of $2.11 \mu \mathrm{mol} / \mathrm{g}$. In a recent study, a $S_{B E T}$ of $1.07 \mathrm{~m}^{2} / \mathrm{g}$ and a $\mathrm{n}_{\mathrm{m}}$ of $2.82 \mu \mathrm{mol} / \mathrm{g}$ were reported for bagasse fiber [20]. These parameters change significantly with the fibers' nature and the fiber extraction process. Cordeiro et al. $[17,18]$ reported $S_{\text {BET }}$ values between 0.382 and $2.793 \mathrm{~m}^{2} / \mathrm{g}$ and $\mathrm{n}_{\mathrm{m}}$ values between 0.3 and $7.4 \mu \mathrm{mol} / \mathrm{g}$ for different lignocellulosic materials.

\subsection{Hot water pre-extraction process}

The hot water pre-extraction of bagasse was carried out in a pulping reactor as described in Section 2.2. This pre-extraction had two objectives: (i) reducing materials in the bagasse, which reduces the yield and the need for the consumption of chemicals for their removal; and (ii) recovering the hemicelluloses based on a biorefinery concept.

Hot water pre-extraction may destroy the acetyl and furfural acid substitutions on hemicelluloses' chemical structure, and generate acetic acid and other low molecular organic acids. The formation of organic acids may contribute to the break of ether bonds located in the fiber cell wall, and promote the production and removal of oligosaccharides, which can be hydrolyzed to produce single sugars. Some single sugars may further degrade into aldehydes [23]. This makes the hot water pre-extraction in an autohydrolysis similar to acid hydrolysis in the way that it leads to unwanted side reactions at elevated temperatures, which lowers the overall yield of hemicelluloses recovery [24]. In addition, the temperature significantly affects the dielectric constant of liquid solution; therefore, water also plays the role of acid at high temperature for sugars' degradation. 
Conventional Gas Chromatography

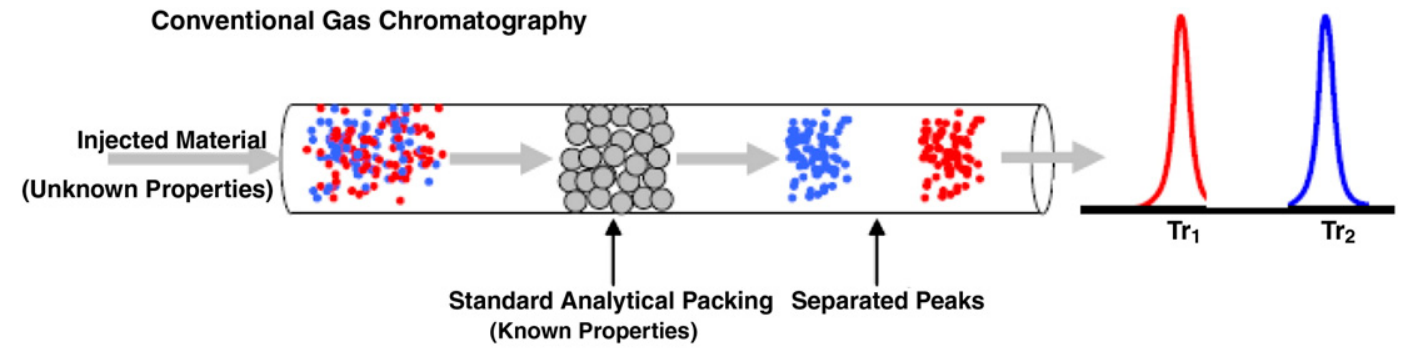

Inverse Gas Chromatography

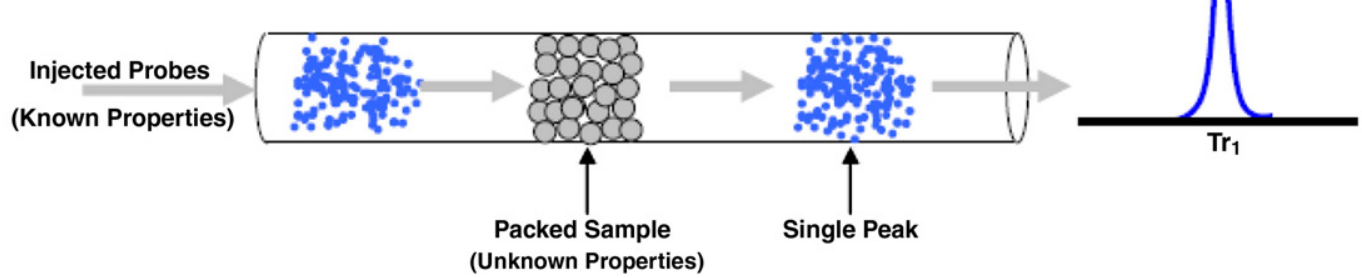

Fig. 1. Schematic representation of conventional GC and IGC [16].

The surface properties of lignocellulosic materials, in particular the $\gamma_{\mathrm{S}}^{\mathrm{D}}$ and acid-base character, were dependent on the chemical composition of the material, namely the amount of the extractives, cellulose, hemicelluloses and lignin components. The interpretation of the IGC results obtained on lignocellulosic materials is difficult, mainly due to the complex nature of bio-fibers. From a chemical point of view, different functional groups exist on the surface. Morphologically, the surface texture and surface morphology at the molecular scale are complex and difficult to evaluate. As compared to the un-extracted sample, the pre-extracted bagasse presents a smaller $\gamma_{S}^{\mathrm{D}}$ value (Table 1 ). Once the non-polar probe interacts only through dispersive interaction, the decrease in the $\gamma_{\mathrm{S}}^{\mathrm{D}}$ of the pre-extracted bagasse indicates that the bagasse surface has become less hydrophilic.

During the extraction process, some hemicelluloses and lignin were removed and made open structure. As the lignin is less hydrophilic than cellulose and hemicelluloses [13], the decrease (from 46.00 to $43.90 \mathrm{~mJ} / \mathrm{m}^{2}$ ) in the $\gamma_{\mathrm{S}}^{\mathrm{D}}$ was observed. In a previous work, a similar decrease was observed when the bagasse fiber was subjected to $1 \%$ of $\mathrm{NaOH}$ extraction [25]. Also, the same reduction in the $\gamma_{\mathrm{S}}^{\mathrm{D}}$ values has been reported after steam explosion of bio-fibers [26], attributed to the protective coating formed by the moieties created by the partial depolymerization of lignin.

The hot water pre-extraction had a slight decreasing effect in the acid-base character, continuing the surface with a basic character predominance $\left(K_{b} / K_{a}=2.78\right)$. The more significant effect of the hot water pre-extraction was felt in the particle morphology. The $S_{\mathrm{BET}}$ of the pre-extracted increase of $55 \%$ compared to that of the raw bagasse (Table 2), which means a significant decrease in the particle size and/or an increase in its porosity, increases the contact area between the fibrous material and the pulping liquor.

Usually, the decrease in the particle size provokes the particle compaction and a consequent decrease in the DP. As a slight increase

Table 1

Dispersive component of surface energy, $\gamma_{\mathrm{S}}^{\mathrm{D}}$, and acid-base constant for bagasse raw and pulp with and without hot water pre-extraction, at $293 \mathrm{~K}$.

\begin{tabular}{lllll}
\hline Samples & $\gamma_{\mathrm{S}}^{\mathrm{D}}\left(\mathrm{mJ} / \mathrm{m}^{2}\right)$ & $\mathrm{K}_{\mathrm{a}}$ & $\mathrm{K}_{\mathrm{b}}$ & $\mathrm{K}_{\mathrm{b}} / \mathrm{K}_{\mathrm{a}}$ \\
\hline Raw bagasse & $46.00(1.61)^{\mathrm{a}}$ & 0.09 & 0.26 & 2.89 \\
Pre-extracted bagasse & $43.90(0.66)$ & 0.09 & 0.25 & 2.78 \\
Pulp raw bagasse & $48.13(1.20)$ & 0.10 & 0.21 & 2.10 \\
Pulp pre-extracted bagasse & $48.43(0.58)$ & 0.10 & 0.21 & 2.10 \\
\hline
\end{tabular}

a The values in parentheses are the standard deviation. in the DP was observed, an increase in the porosity of the material can occur [16].

\subsection{Pulping process}

The results of the experiments on the pulping of pre-extracted and un-extracted bagasse materials are given in Table 3. The pulping process with $11 \%$ of active alkali, produced pulps with high Kappa numbers and contained too much un-cooked material, which was difficult to disintegrate into fibers, making it impossible to obtain hand sheets. The pulps prepared using $14 \%$ of active alkali showed that either lignin precipitation had occurred, and/or lignin within the fiber walls had not been sufficiently removed, as indicated by the high Kappa number. To obtain bleachable-grade bagasse pulps, the charge of active alkali used had to be increased. Effectively, increasing the active alkali charges from 11 to $17 \%$, decreased the Kappa number, while the screened pulp yield showed an increase. The active alkali above 17\% generally led to limited improvements in screened pulp yield and the Kappa number. Pulping with a charge of $17 \%$ active alkali showed to be sufficient to ensure almost complete elimination of the non-cellulosic matter. Therefore, any further increase in the chemical concentration above this value was found to be unnecessary.

Table 3 also shows the effect of hot water pre-extraction on the soda pulping of bagasse. It was seen that the hot water preextraction of bagasse resulted in lower Kappa number of pulp with considerable lowering of pulp reject. Similar results were observed by Jahan et al. [5] for rice straw pulping with soda-anthraquinone. In acidic or alkaline hydrolysis, the hemicelluloses have higher accessibility compared to the cellulose, due to their amorphous structure and a much lower degree of polymerization [27]. As referred above, the hot water pre-extraction results in bagasse with a more open structure and the migration of the lignin to the surface. Furthermore,

Table 2

BET specific surface area $\left(\mathrm{S}_{\mathrm{BET}}\right)$, monolayer capacity $\left(\mathrm{n}_{\mathrm{m}}\right)$ and permeability (DP) obtained with n-octane bagasse raw and pulp with and without hot water pre-extraction, at $293 \mathrm{~K}$.

\begin{tabular}{llll}
\hline Samples & $\mathrm{S}_{\mathrm{BET}}\left(\mathrm{m}^{2} / \mathrm{g}\right)$ & $\mathrm{n}_{\mathrm{m}}(\mu \mathrm{mol} / \mathrm{g})$ & $\mathrm{DP}\left(\mathrm{cm}^{2} / \mathrm{s}\right)$ \\
\hline Raw bagasse & $0.80(0.012)^{\mathrm{a}}$ & $2.11(0.063)$ & $0.081(0.001)$ \\
Pre-extracted bagasse & $1.24(0.027)$ & $3.27(0.033)$ & $0.085(0.003)$ \\
Pulp raw bagasse & $1.15(0.044)$ & $3.02(0.063)$ & $0.177(0.007)$ \\
Pulp pre-extracted bagasse & $1.42(0.026)$ & $3.68(0.084)$ & $0.319(0.011)$ \\
\hline
\end{tabular}

a The values in parentheses are the standard deviation. 
Table 3

Laboratory soda pulping results for bagasse with and without hot water pre-extraction.

\begin{tabular}{|c|c|c|c|c|c|c|c|c|c|}
\hline \multirow[t]{2}{*}{ Sample } & \multicolumn{3}{|c|}{$11 \%$ active alkali } & \multicolumn{3}{|c|}{$14 \%$ active alkali } & \multicolumn{3}{|c|}{$17 \%$ active alkali } \\
\hline & $\begin{array}{l}\text { Yield }^{\mathrm{a}} \\
(\%)\end{array}$ & $\begin{array}{l}\text { Reject }^{\mathrm{b}} \\
(\%)\end{array}$ & $\begin{array}{l}\text { Kappa } \\
\text { no. }\end{array}$ & $\begin{array}{l}\text { Yield } \\
(\%)\end{array}$ & $\begin{array}{l}\text { Reject } \\
(\%)\end{array}$ & $\begin{array}{l}\text { Kappa } \\
\text { no. }\end{array}$ & $\begin{array}{l}\text { Yield } \\
(\%)\end{array}$ & $\begin{array}{l}\text { Reject } \\
(\%)\end{array}$ & $\begin{array}{l}\text { Kappa } \\
\text { no. }\end{array}$ \\
\hline Un-extracted & $\begin{array}{l}34.5 \\
(0.8)^{\mathrm{c}}\end{array}$ & $\begin{array}{l}10.6 \\
(0.6)\end{array}$ & $\begin{array}{l}54 \\
(2.1)\end{array}$ & $\begin{array}{l}40.6 \\
(0.75)\end{array}$ & $\begin{array}{l}2.5 \\
(0.3)\end{array}$ & $\begin{array}{l}28.4 \\
(1.5)\end{array}$ & $\begin{array}{l}51.1 \\
(0.3)\end{array}$ & $\begin{array}{l}0.0 \\
(0.0)\end{array}$ & $\begin{array}{l}19.3 \\
(0.4)\end{array}$ \\
\hline Pre-extracted & $\begin{array}{l}45.3 \\
(0.7)\end{array}$ & $\begin{array}{l}6.3 \\
(0.4)\end{array}$ & $\begin{array}{l}40 \\
(1.3)\end{array}$ & $\begin{array}{l}46.6 \\
(0.5)\end{array}$ & $\begin{array}{l}3.2 \\
(0.2)\end{array}$ & $\begin{array}{l}26.6 \\
(1.1)\end{array}$ & $\begin{array}{l}56.9 \\
(0.3)\end{array}$ & $\begin{array}{l}0.0 \\
(0.0)\end{array}$ & $\begin{array}{l}18.6 \\
(0.3)\end{array}$ \\
\hline
\end{tabular}

a Screened yield.

b Screened reject.

c The values in parentheses are the standard deviation.

the increased available surface area, shown by IGC results, caused by hemicellulose degradation and partial delignification in hot water extraction, improves the susceptibility towards delignification with alkaline solutions. Therefore, the delignification was faster for pulping of pre-extracted samples, and the pulp yielded a lower Kappa number, even with a lower (11\%) alkali charge. In general, the total pulp yield and Kappa number decreased with an increasing alkali charge (Table 3). At $17 \%$ alkali charge, the pre-extracted bagasse showed $5.8 \%$ higher pulp yield, compared to the un-extracted bagasse.

In relation to the surface properties, the bagasse material after the pulping process shows an increase in the $n$-alkane interaction (Fig. 2), which means an increase in the $\gamma_{\mathrm{S}}^{\mathrm{D}}$ due to the increase in the samples' hydrophilicity. This increase can be associated with the increase in number and/or in the energy of the active sites. Considering the energetic profile for the non-polar probe (Fig. 3), the pulp presents active sites with similar energy $\left(A_{\max }\right.$ around $\left.10-11 \mathrm{~kJ} / \mathrm{mol}\right)$ but in higher numbers, justifying the increase in the $\gamma_{S}^{\mathrm{D}}$. During the pulping process the cellulose content increases in the material, with lignin and hemicellulose extraction and the hydroxyl groups more exposed at the surface. As the cellulose is a macromolecule, more hydrophilic that lignin, this increase was expected and was in good agreement with the observations by Duarte [3].

The energetic profile (Fig. 4a) shows the tetrahydrofuran, the probe with higher ratio electron donor/acceptor $\mathrm{dN} / \mathrm{dA}$ - basic probe, showed that the samples have more energetic active sites after the pulping process. On the other hand, for probe with lower $\mathrm{dN} / \mathrm{dA}$, ethanol - the acid probe - it was observed that there was an increase in the less energetic active sites (Fig. 4b). Taking into account all the polar probes, a ratio $\mathrm{K}_{\mathrm{b}} / \mathrm{K}_{\mathrm{a}}$ of 2.10 was found, meaning a decrease in the bagasse surface basicity.

In terms of the fiber morphology, namely the $\mathrm{S}_{\mathrm{BET}}$, a significant increase was detected, with more relevance to the bagasse not subjected to the hot water pre-extraction. The pulp obtained from pre-extracted

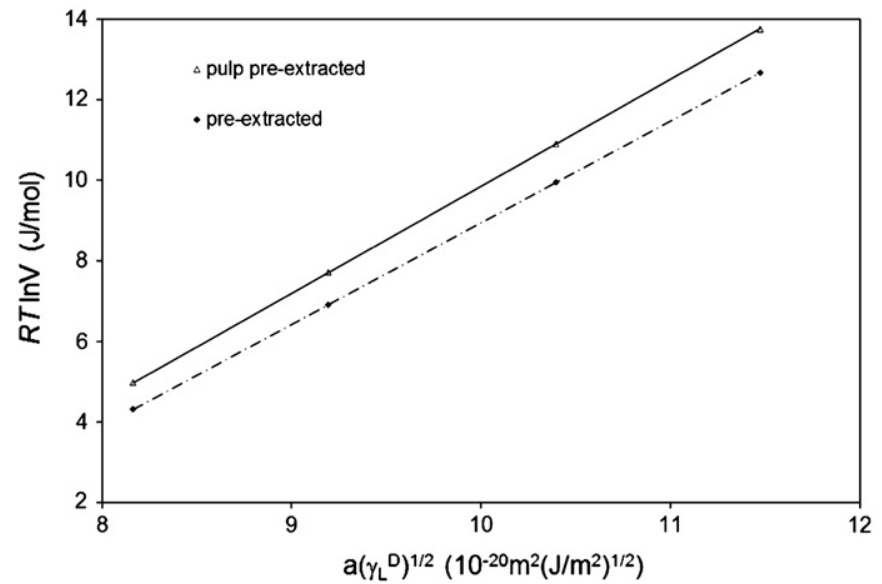

Fig. 2. Plot of $R T \ln \mathrm{V}_{\mathrm{N}}$ versus $a\left(\gamma_{\mathrm{L}}^{\mathrm{D}}\right)^{1 / 2}$ for $n$-alkane probes onto pre-extracted bagasse, at $293 \mathrm{~K}$. bagasse shows higher $S_{B E T}$ and $n_{m}$ due to a decrease in the particle size and/or an increase in its porosity. The observed increase in the DP (Table 3), which means a more permeable material and less fiber compaction, can indicate a higher porosity in the bagasse after the pulp process. This result is consistent with previous research findings $[3,28]$.

\section{Conclusions}

Based on this study the following conclusions can be drawn:

a) Screened yield and Kappa number of the pulps improved with an increasing alkali charge from $11 \%$ to $17 \%$. In addition, pre-extracted samples showed higher yields and lower Kappa numbers compared to the un-extracted ones;

b) IGC showed that the pulp process changes the active sites, responsible for the physico-chemical activity of the surface of the bagasse. An improvement in the hydrophilicity of the surface material and a decrease in the basicity surface were detected;

c) The hot water pre-extraction gave rise to bagasse material with smaller $\gamma_{S}^{\mathrm{D}}$ but the more significant effect was in the particle morphology, where the particles have higher surface area and permeability, increasing the interaction between the fibrous material and the pulping solution; and

d) The surface pulps obtained from un-extracted and pre-extracted bagasses have similar hydrophobicity and acid-base characteristics. However, the pre-extracted pulp presents particles with smaller size and more porosity.

\section{Acknowledgments}

Portuguese authors would like to thank the "Programa Nacional de Re-equipamento Científico", POCI 2010, by sponsored IGC work (FEDER and Foundation for the Science and Technology). The Iranian authors

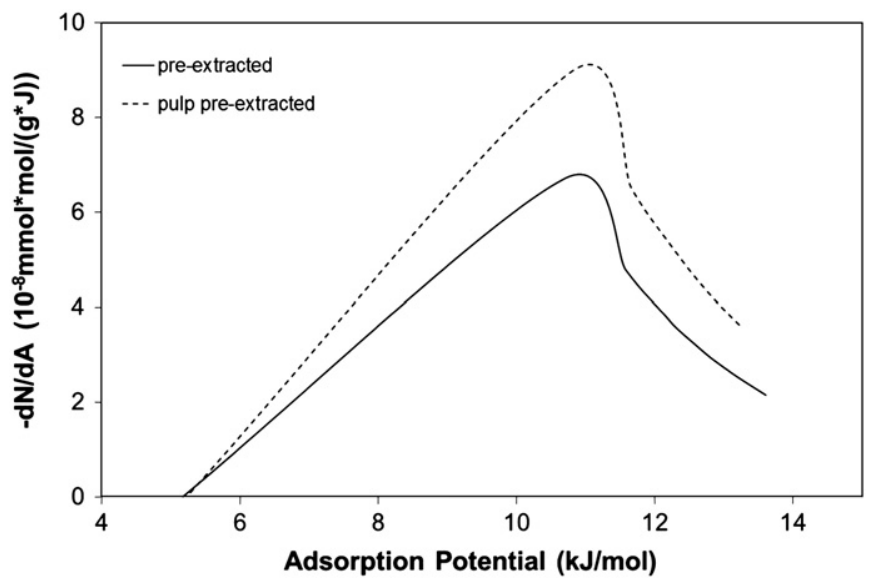

Fig. 3. Heterogeneity profiles obtained with n-octane for hot water pre-extracted bagasse and the pulp, at $293 \mathrm{~K}$. 

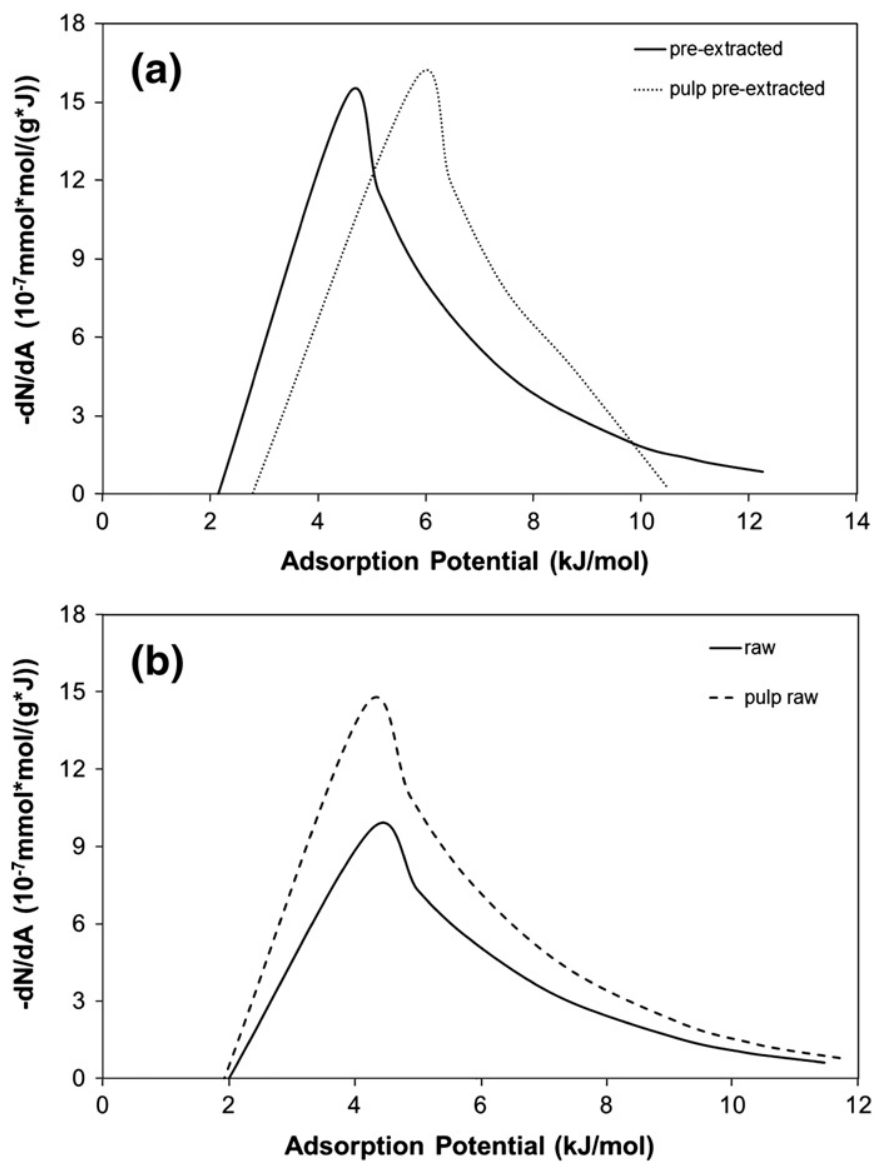

Fig. 4. Heterogeneity profiles obtained with tetrahydrofuran (a) and ethanol (b) in the bagasse, at $293 \mathrm{~K}$.

gratefully acknowledge the financial support (grant \# 89000873) from the Iran National Science Foundation (INSF).

\section{References}

1] A. Chikako, N. Yoshitoshi, K. Fumihisa, Biotechnol. Bioprocess Eng. 10 (2005) 346.

[2] A. Mittal, G.M. Scott, T.E. Amidon, D.J. Kiemle, A.J. Stipanovic, Bioresour. Technol. 100 (2009) 6398.

[3] G. Duarte, Ph.D. Dissertation, State University of New York, USA, (2010).

[4] H. Lu, R. Hu, A. Ward, T.E. Amidon, B. Liang, S. Liu, Biomass Bioenergy 39 (2012) 5.

[5] M.S. Jahan, M. Shamsuzzaman, M. Mostafizur Rahman, S.M. Iqbal Moeiz, Y. Nic, Ind. Crops Prod. 37 (2012) 164.

[6] S. Caparrós, M.J. Díaz, J. Ariza, F. López, L. Jiménez, Bioresour. Technol. 99 (2008) 741.

[7] W.W. Al-Dajani, U.W. Tschirner, Tappi J. 7 (2008) 3.

[8] Y. Hamzeh, A. Ashori, Z. Khorasani, A. Abdulkani, A. Abyaz, Ind. Crops Prod. 43 2013) 365.

[9] C.V.T. Mendes, M.G.V.S. Carvalho, C.M.S.G. Baptista, J.M.S. Rocha, B.I.G. Soares, G.D.A. Sousa, Food Bioprod. Process. 87 (2009) 197.

[10] M.S. Jahan, A. Saeed, Y. Ni, Z. He, J. Biobased Mater. Bioenergy 3 (2009) 380.

[11] M.S. Tunc, A.R.P. van Heiningen, Holzforschung 62 (2008) 539

[12] S. Sousa, R. Simões, A.P. Duarte, Cellul. Chem. Technol. 41 (2007) 301.

[13] C. Piao, J.E. Winandy, T.F. Shupe, Wood Fiber Sci. 42 (2010) 1.

[14] N. Cordeiro, M.N. Belgacem, I.C. Torres, J.V.C.P. Moura, Ind. Crops Prod. 19 (2004) 147.

[15] V. Gutmann, The Donor-Acceptor Approach to Molecular Interactions, Plenum Publ. Corp, New York, 1978.

[16] I.M. Moutinho, 2009. Ph.D. Dissertation., Universidade de Coimbra, Portugal (2009).

[17] N. Cordeiro, C. Gouveia, M. Jacob John, Ind. Crops Prod. 33 (2011) 108.

[18] N. Cordeiro, C. Gouveia, A.G.O. Moraes, Carbohydr. Polym. 84 (2011) 110.

[19] N. Cordeiro, C. Mendonça, L.A. Pothan, A. Varma, Carbohydr. Polym. 88 (2012) 125.

[20] N. Cordeiro, M. Ornelas, A. Ashori, S. Sheshmani, H. Norouzi, Carbohydr. Polym. 87 (2012) 2367.

[21] R.H. Mills, D.J. Gardner, R. Wimmer, J. Appl. Polym. Sci. 110 (2008) 3880.

[22] J. Condor, C. Young, Physicochemical Measurement by Gas Chromatography, John Wiley and Sons, Chichester, UK, 1979.

[23] S.-F. Zhang, H. Yang, Adv. Mater. Res. 236-238 (2011) 1174.

[24] E. Palmqvist, B. Hahn-Hägerdal, Bioresour. Technol. 74 (2000) 25.

[25] A. Ashori, M. Ornelas, S. Sheshmani, N. Cordeiro, Carbohydr. Polym. 88 (2012) 1293.

[26] A. Bismarck, I. Aranberri-Askargorta, J. Springer, T. Lampke, B. Wielage, A. Stamboulis, I. Shenderovich, H.H. Limbach, Polym. Compos. 23 (2002) 872.

[27] S.-H. Yoon, K. Macewan, A. Van Heiningen, Tappi J. 7 (2008) 27.

[28] J.J.P. Heller, Ph.D. Dissertation, University of Maine, USA (2009). 